\title{
The optical design and performance of a concentrator photovoltaic module
}

\author{
Ross Dane Schultz \\ Ernest E van Dyk \\ Frederik J Vorster
}

Centre for Energy Research, Department of Physics, Nelson Mandela Metropolitan University, Port Elizabeth, South Africa

\begin{abstract}
Concentration photovoltaic (CPV) modules promise a more efficient, higher power output than traditional photovoltaic modules. This is achieved by concentrating sunlight onto a small $1 \mathrm{~cm} 2$ concentrator triple-junction (CTJ) InGaP/InGaAs/Ge cell by using high quality precision optics. In order to achieve high energy performance and reliability, well thought-out design decisions must be made in the development of a CPV module. This paper investigates the design of two CPV modules (Module I and II), which are based on the Sandia III Baseline Fresnel module. The investigation concentrated on the effect of the optimization of the optical design on the electrical performance characteristics of CTJ cells with good thermal dissipation. The best performance achieved by Module I was at 336 times operational concentration (Xo), which produced a Pmax of $10.29 \mathrm{~W}$ per cell, with cell and module efficiencies of $39 \%$ and $24 \%$, respectively. In the development of the second module (Module II) pre-deployment criteria such as the CTJ cell and system components characteristics was used to eliminate faulty components from the system what was observed in Module I. Cell units that were optimized in Module II showed no form of degradation in their Current-Voltage (I-V) characteristics. The cell unit operating under optical misalignment showed a progressive degradation with long term operation in the field.
\end{abstract}

Keywords: concentrator photovoltaics, concentrated triple junction cells, efficiency, degradation.

\section{Introduction}

Concentrator photovoltaic (CPV) systems offer a cost effective alternative to flat plate photovoltaics (PV) to address the power challenge faced by nations (Hegedus \& Luque, 2002; Cotal et al., 2009; Kost et al., 2014).. A report by IMS Research states that advances in CPV technology could drive down costs by $16 \%$ annually, which will create an increase in installations globally from 2012's cumulative total of around $160 \mathrm{MW}$ to $3 \mathrm{GW}$ by 2016 . Based on these figures, a projection of 0.14US $\$$ / kWh for 2015 was made (Kost et al., 2014). This may be a cost effective technology to deploy to meet the $3725 \mathrm{MW}$ goal as set in the Integrated Resource Plan (IRP) (Chong \& Siav, 2008).

This is achieved by replacing the standard flatplate PV silicon cells with smaller, highly efficient III$\mathrm{V}$ multi-junction cells (MJC) (Hegedus \& Luque, 2002). The remainder of the module comprises of relatively cheap optical elements such as lenses and mirrors, which collect, concentrate and evenly distribute the direct incident solar flux onto the CTJ cell. These CPV systems are present today in South Africa and are operational at Touwsrivier and showcased at Megawatt Park by Soitec Solar. As from 25 March 2014, 22 MW of the planned 44 MW has been installed and operational at Touwsrivier (Chong \& Siav, 2008).

This paper addresses some crucial design considerations needed to manufacture an operational, field-ready CPV module. The first module (Module I) was based on the Sandia III Baseline Fresnel module design (Hegedus \& Luque, 2002), which utilizes a Fresnel lens as the primary concentrating optical element to concentrate incident light and a truncated reflector lens as the secondary optical element to distribute the concentrated light evenly 
onto a concentrator triple-junction (CTJ) InGaP/ InGaAs/Ge cell. Performance parameters were measured, and the findings obtained from Module I were used as an evolutionary step to improve the design of Module II. Module II was a new design using separate cell units, which were interconnected to form the module. This design facilitated experimentation and easy unit replacement, without decommissioning the entire module. The Module cell units that were tested under optimal design conditions showed no form of degradation after 228 sun-hours of operation under concentration, while degradation was seen in non-optimised units.

\section{Theory}

\subsection{Concentrating sunlight}

\section{Concentration factor}

In the CPV systems that were used in this study, parallel light rays from the direct normal solar irradiance (DNI) that are incident onto a primary optical element are concentrated on a secondary optical element. The secondary element distributes the intensity and spectral content of the concentrated light homogeneously across the area of the CPV receiver (CTJ) as illustrated in Figure1.

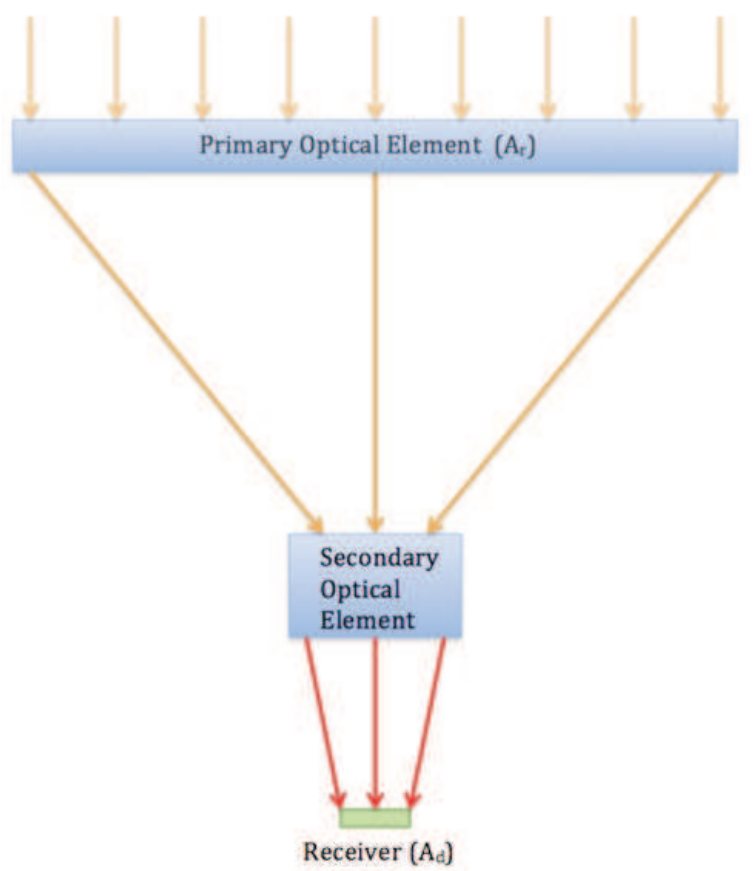

Figure 1: Schematic illustration showing the basic operation of a CPV module

The increased photon flux on the CTJ results in increased photocurrent density and hence, will lead to an increased power output from the CTJ (Kost et al., 2014; Chong \& Siaw, 2008; Rumyantsevm et al., 1997).

CPV systems are classified according to concentration ratio. The geometric concentration ratio $\left(\mathrm{X}_{\mathrm{g}}\right)$ that is sometimes used is defined as:

$$
X_{g}=\frac{A_{r}}{A_{d}}
$$

Where $A_{r}$ is the primary lens area and $A_{d}$ is the MJC cell aperture area. This does not account for any optical, thermal and electrical losses. In this work we used the operational concentration $\left(\mathrm{X}_{\mathrm{o}}\right)$, which takes the optical losses into account. $\mathrm{X}_{\mathrm{O}}$ is the ratio of the concentrated irradiance in the device plane after optical losses $\left(\operatorname{Ir}_{\mathrm{x}}\right)$ and the DNI non-concentrated irradiance $\left(\operatorname{Ir}_{1}\right)$ incident on the primary lens.

$\mathrm{X}_{\mathrm{O}}$ is defined as:

$$
\mathrm{X}_{\mathrm{o}}=\frac{\operatorname{Ir}_{\mathrm{x}}}{\operatorname{Ir}_{1}}
$$

Assuming that there is a linear relationship between the irradiance (Ir) and short circuit current of the CTJ cell (Isc) under un-concentrated $\left(\mathrm{Ir}_{1}\right)$ as well as concentrated irradiance $\left(\operatorname{Ir}_{\mathrm{x}}\right)$ Rumyantsevm et al., 1997):

$$
\mathrm{Ir}=\mathrm{F} . \mathrm{I}_{\mathrm{sc}}
$$

Where the factor $\mathrm{F}$ relates the short circuit current $\left(\mathrm{I}_{\mathrm{sc} 1}\right)$ to irradiance. Using the linear relationship expressed in Equation 3, the expression for $\mathrm{X}_{\mathrm{O}}$ in terms of the concentrated short circuit current $\left(\mathrm{I}_{\mathrm{scx}}\right)$ as seen in Equation 2 may be rewritten as:

$$
\mathrm{X}_{\mathrm{o}}=\frac{\mathrm{Isc}_{\mathrm{x}}}{\mathrm{Isc}_{1}}
$$

Equation 4 thus gives an operational concentration factor that takes into account optical and electrical interactions, misalignments and optical performance acting on the CTJ cell.

\subsection{Short circuit current density}

The short circuit current density $\mathrm{J}_{\mathrm{sc}}$ produced by a CTJ cell is more complex than that from a singlejunction cell as the sub-cells are series-connected. For a single cell, the current density is defined in Equation 5 as:

$$
\mathrm{J}_{\mathrm{sc}}=\int \mathrm{S}(\lambda) \cdot \Phi_{\text {inc }}(\lambda) \mathrm{d} \lambda
$$

where $S$ is the spectral response and $\Phi_{\text {inc }}$ is the incident concentrated solar spectrum (Hegedus \& Luque. 2002; Kost et al., 2014; Kinsey \& Edmondson, 2009).

Since the device is series-connected, the overall current generation from the device will be limited to the lowest current generator. Equation 6 shows the current density generated from the CTJ cell under concentration (Hegedus \& Luque, 2002):

$$
\mathrm{J}_{\mathrm{scx}}=\operatorname{Min}\left[\int \mathrm{S}(\lambda) \cdot \Phi_{\mathrm{inc}}(\lambda) \mathrm{d} \lambda\right]
$$




\subsection{Open circuit voltage}

The $V_{o c}$ produced by a CTJ cell is the sum of the $\mathrm{V}_{\mathrm{oc}}$ contribution for each sub-cell given in Equation 7 (Lorenzo, 1994):

$$
\mathrm{V}_{\mathrm{ocx}}=\sum \mathrm{V}_{\mathrm{oci}}
$$

where $V_{o c x}$ is the open circuit voltage of the CTJ cell and $V_{\text {oci }}$ is the individual $V_{\text {oc }}$ of each sub-cell (Hegedus \& Luque, 2002). The $\mathrm{V}_{\text {oc }}$ for an individual sub-cell is:

$$
V_{\text {oci }}=\frac{n k T}{q} \ln \left(\frac{I_{s c x}}{I_{0}}\right)
$$

where $\mathrm{k}$ is Boltzmann's constant, $\mathrm{T}$ the temperature of the CTJ cell, q the elemental charge of an electron, $\mathrm{n}$ is the ideality factor and $\mathrm{I}_{\mathrm{o}}$ the saturation current for the semiconductor material. Since the same current passes through the sub-cell, each sub-cell will have the same concentration factor. Therefore, the most basic expression for the $\mathrm{V}_{\text {ocx }}$ for the CTJ device can be written as (Hegedus \& Luque, 2002; Cotal et al., 2009):

$$
\mathrm{V}_{\mathrm{ocx}}=\mathrm{V}_{\mathrm{oc} 1}+\frac{\mathrm{nkT}}{\mathrm{q}} \ln \left(\mathrm{X}_{\mathrm{o}}\right)
$$

where $V_{\text {oc1 } 1}$ is the $V_{\text {oc }}$ of the CTJ cell at one-sun concentration and $\mathrm{X}_{\mathrm{o}}$ is the operational concentration.

\subsection{Power, fill factor and efficiency}

Defining the power and efficiency is important as these features act as a tool to identify the performance of an H-CPV module.

\subsubsection{Efficiency}

The efficiency of a CTJ cell and HCPV module can be defined as:

- cell efficiency $\left(\eta_{c}\right)$

$\eta_{\mathrm{c}}=\frac{\mathrm{P}_{\text {out }}}{\mathrm{P}_{\text {in }}} \times 100=\frac{\mathrm{V}_{\mathrm{c}(\max )} \cdot \mathrm{I}_{\mathrm{c}(\max )}}{\mathrm{X}_{\mathrm{o}} \cdot \mathrm{I}_{\mathrm{d}} \cdot \mathrm{A}} \times 100$

where $\mathrm{Ir}_{\mathrm{d}}$ is the direct normal irradiance and $\mathrm{A}$ is the area of the cell (Hegedus \& Luque, 2002; Cotal et al., 2009).

- module efficiency $\left(\eta_{m}\right)$.

$\eta_{\mathrm{m}}=\frac{\mathrm{P}_{\text {out }}}{\mathrm{P}_{\text {in }}} \times 100=\frac{\mathrm{V}_{\mathrm{m}(\max )} \mathrm{I}_{\mathrm{m}(\mathrm{max})}}{\mathrm{I}_{\mathrm{d}} \cdot \mathrm{A}_{\mathrm{m}}} \times 100$

where $I_{d}$ is the direct normal irradiance and $A_{m}$ is the area of the module (Ventre \& Messenger, 2005; Vorster, 2001).

\subsection{Sun-hours}

The number of peak sun-hours is numerically identical to the average daily solar insolation for the location. Hence, the number of sun-hours available to a PV system is defined as the ratio of the total energy available for the monitoring period (typically a day) to $1 \mathrm{~kW} \cdot \mathrm{m}^{-2}$ as shown in Equation 14:

$$
\text { Sunhours }=\sum_{1}^{\mathrm{n}} \mathrm{t} \times \frac{\left(\mathrm{Ir}_{\mathrm{n}}+\mathrm{Ir}_{\mathrm{n}+1}\right)}{2 \times 1 \mathrm{~kW} \cdot \mathrm{m}^{-2}}
$$

where I $r_{n}$ and $I r_{n+1}$ are the consecutive irradiance measurements for the monitoring period and $t$ is the measurement time interval, measured in hours (Hegedus \& Luque, 2002; Lorenzo, 1994).

\subsection{CPV optical systems}

One of the most important parts of the operation of $\mathrm{CPV}$ systems is the optical configuration and the precision and quality of the optical elements (Hegedus \& Luque, 2002;; Rumyantsevm et al., 1997; Schultz et al., 2011; Xie et al., 2011). To achieve maximum energy yield, the optical elements need to transmit (in the case of refractive optics) or reflect (in the case of reflective optics) as much sunlight as possible in the wavelength range that is influenced by the quantum efficiency of the CTJ cell.

\subsubsection{Primary Fresnel optics}

A Fresnel lens is a light, thin, relatively flat lens used to concentrate incident sunlight by making use of concentric reflective or refractive facets known as Fresnel zones (Hegedus \& Luque, 2002; Kwangsun Ryu (2006); Leutz \& Rhodes, 2001). Refractive Fresnel lenses are usually made out of an acrylic, Poly(methyl methacrylate) (PMMA) or polycarbonate materials and are manufactured by compression moulding (Leutz \& Rhodes, 2001). This allows for the manufacturing of single and parquet lenses in any shape or size.

\subsubsection{Secondary optics}

The main function of the secondary optical elements is to increase the acceptance angle to capture more concentrated and stray light from the primary optical element and to distribute the concentrated solar flux uniformly across the device's surface. Reflective secondary elements utilise mirrors in the form of highly reflective aluminium sheeting (Alanod material properties) with reflectance of 95\% to reflect the concentrated incident solar light towards the cell's surface. Refractive secondary elements utilise specially shaped refractive material that refracts the light onto the cell's surface. The refractive secondary element is usually in optical contact with the cell's surface in order to transfer as much light as possible to the cell, reducing any loss that would result from spillage from the sides of the interface. 


\subsection{Multi-junction cells}

Multi-junction cells offer a better absorption of photon energy from a wider spectral range than conventional PV cells do (Hegedus \& Luque, 2002; Rumyantsevm et al., 1997). The use of doped silicon as a semiconductor material only utilises a small fraction of the solar spectrum limited by the band gap of the material. To increase the performance and power output of a CPV cell, a multi-junction device is created to allow for more absorption from the solar spectrum. This is achieved by creating a device structure, which utilises vertically stacked multiple sub-cells connected in series (Vincenzo Fracastoro et al., (2009). The sub-cells are made from materials that have quantum efficiency profiles that span the solar spectrum range from $300 \mathrm{~nm}$ to $1800 \mathrm{~nm}$. This allows for a much larger portion of the solar spectrum to be absorbed, resulting in a higher performance (Hegedus \& Luque, 2002; (Hegedus \& Luque, 2002; Vincenzo Fracastoro et al., (2009); Ventre \& Messenger, 2005). Figure 2 shows the schematic of three material layers and their relative band gap energies in the multi-junction cell used in the study.

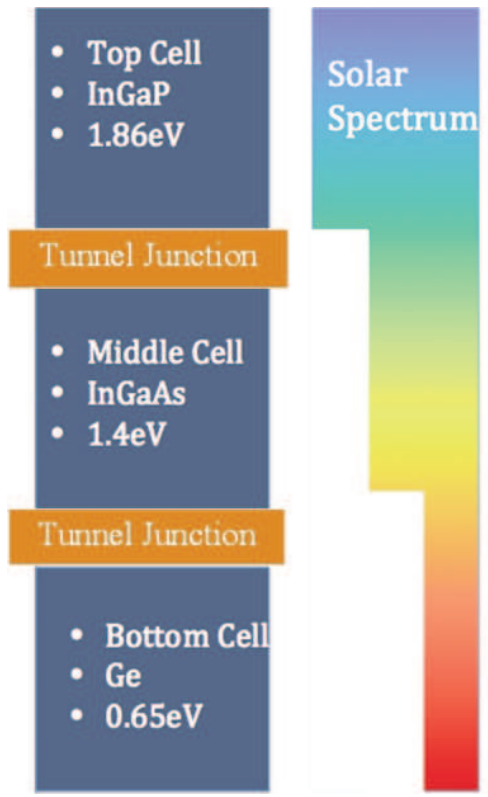

Figure 2: Schematic representation of the band gap energies of the materials used in a CTJ device

The cell assembly used in this study consists of a $1 \mathrm{~cm}^{2}$ triple-junction InGaP/InGaAs/Ge semiconductor material, two bypass diodes and connection terminals mounted on a $6.78 \mathrm{~cm}^{2}$ gold and ceramic base (Emcore datasheet). The InGaP/InGaAs/Ge active layers are monolithically integrated and lattice matched to the Ge substrate. The $3 \mathrm{p}-\mathrm{n}$ junctions are connected in series via tunnel junctions (Hegedus \& Luque, 2002). Figure 3 shows a schematic diagram of the CTJ cell assembly used in the study.

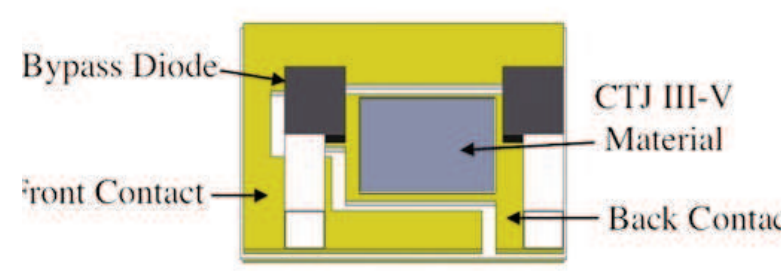

Figure 3: The schematic drawing of the CTJ receiver assembly cell used in the development of the prototype modules

Source: Vincenzo Fracastoro et al. (2009)

The CTJ cell consists of $3 \mathrm{p}-\mathrm{n}$ junctions with spectral responses ranging from $300 \mathrm{~nm}-1800$ $\mathrm{nm}$. Bypass diodes allow for current to bypass the cell in the case of cell mismatch occurring in a CPV module.

\section{CPV module design}

An initial design was used to construct a prototype (Module I) and it was fully characterized with respect to the optics and electrical performance. The results obtained in this investigation were used to improve on the design of a second prototype (Module II), which was then constructed and evaluated.

\subsection{Module I}

Figure 4 shows (a) the schematic and (b) photograph of the experimental CPV module (Module I) developed in the study. As illustrated in Figure 4, the physical structure of the experimental $\mathrm{CPV}$ module was based on the Sandia III Baseline Fresnel Module (Xie et al., 2011) because of its simplistic and compact design. The main structure of the experimental $\mathrm{CPV}$ module was made from aluminium, which supports a $2 \times 4$ Fresnel lens parquet array and 8 assembled CTJ cells attached to secondaries and heatsinks. Concentrating sunlight onto an area using a Fresnel lens without incorporating some form of secondary optical element will result in the formation of a non-uniform illumination intensity distribution across the CTJ's cell surface. This could result in the formation of hot spots, which may lead to low power production, cell damage and premature failure of the cell (Hegedus \& Luque, 2002; Kwangsun et al., 2006; Leutz \& Rhodes, 2001).

A truncated pyramid reflective secondary optical element was used for Module I. The secondary was constructed out of 4 pieces of highly polished mirrored aluminium sheeting (Alanod 95\% (Leutz \& Rhodes, 2001). forming the sides of the truncated pyramid with a square base. To determine the secondary element's dimensions, the focal length of the Fresnel lens and the general shape of the reflective secondary must be considered. The dimensions and angles for the reflective secondary were determined by using a ray-tracing program (IME 

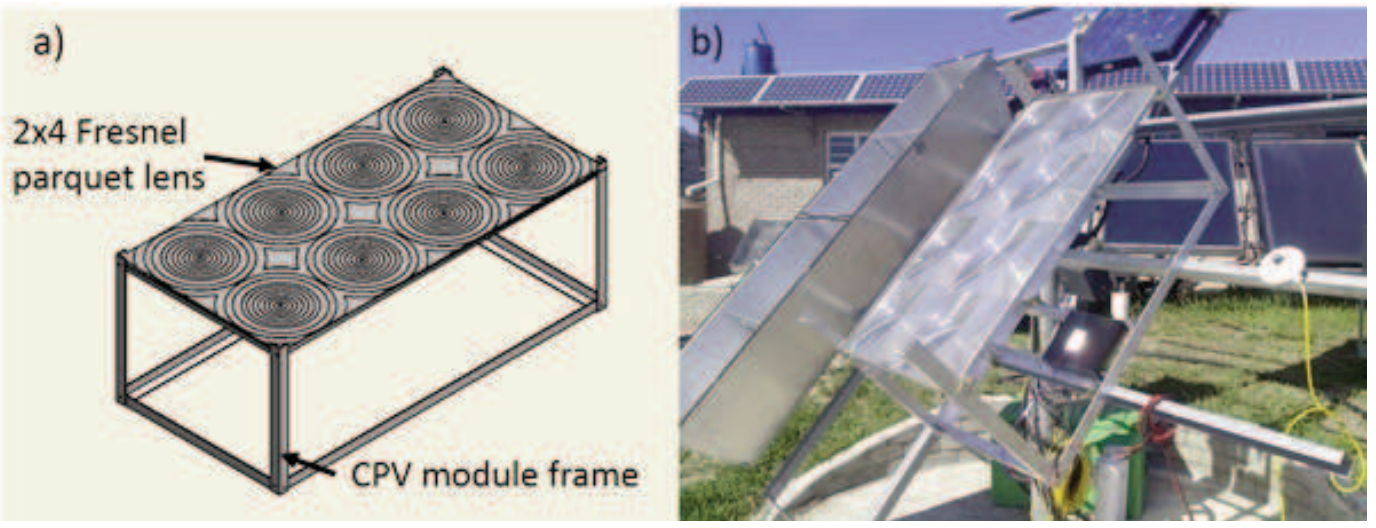

Figure 4: (a) A schematic and (b) photograph of the experimental Module I developed in the study

Raytrace software). A schematic diagram of the reflective truncated secondary used in Module I is shown in Figure 5.

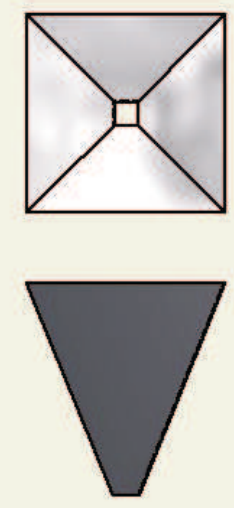

Figure 5: Schematic drawing of the reflective truncated secondary used in Module I

Using ray-tracing, a distance of $23.4 \mathrm{~cm}$ was found to be the optimal distance that allowed a 1 $\mathrm{cm}^{2}$ area of the CTJ cell to be illuminated, while at the same time, showing minimal effect from lens aberrations.

\subsection{Module II}

To reduce the shortcomings observed in Module I, a new experimental CPV module (Module II) was designed. The new modular design comprised of a unit that contained a Fresnel lens, refractive secondary, heatsink and CTJ cell. These individual units were designed to eliminate the need to disassemble the whole module in the case of a single cell failure and to facilitate experimentation. Additionally, the size of the module is not restricted to the number of Fresnel lenses that are available in the parquet array.

Figure 6 shows the schematic diagram of each cell unit. The cell unit comprised of a single PMMA Fresnel lens, which acts as the primary optical element.

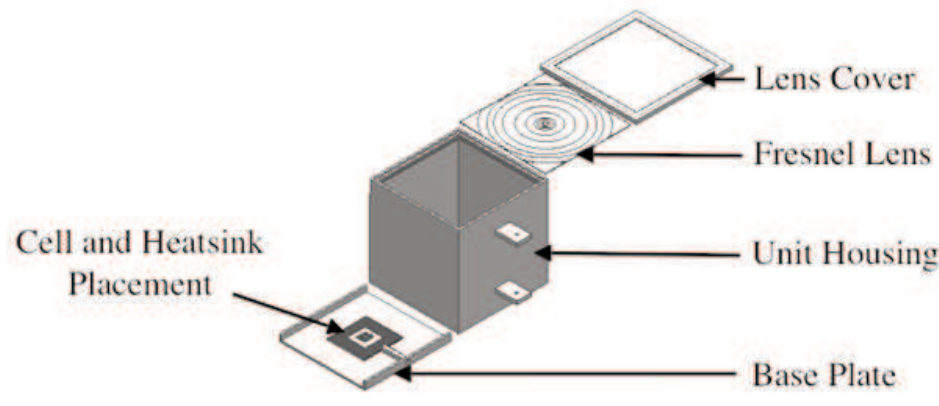

Figure 6: The schematic diagrams of a cell unit used in Module II

The use of a single lens reduced the effects of lens warp and deformation experienced by a larger parquet lens due to wind jarring and tracker movement (Leutz \& Rhodes, 2001). Additionally, this is an easier and cheaper way to replace a single lens than a parquet lens, if damaged.

The box shaped housing of each unit was made from $0.6 \mathrm{~mm}$ galvanized steel that was folded to form a box. The box isolated the internal components of the CPV module from the environment. It also acted as a rigid platform for the mounting of the Fresnel lens and base plate. The housing has fixtures on the side of the box to allow for mounting to the module frame. A heatsink and the CTJ cell with refractive secondary are attached to the baseplate as shown in Figure 6.

Figure 7 shows a schematic drawing of the refractive secondary lens used in Module II. The lens consists of a piece of moulded glass, which is circular in shape with an optical aperture of 8.85 $\mathrm{cm}^{2}$. The circular aperture is shaped down along the sides to form a tapered square with a cell aperture area of $1 \mathrm{~cm}^{2}$ at the base. The refractive secondary is optically coupled to the cell, eliminating soiling of the cell from the environment and reducing the amount of maintenance needed. Figure 8 shows the schematic diagram of the improved CPV module, which comprised of an assembly of 8 of the cell units attached to a support frame.

The cell units were connected electrically in 


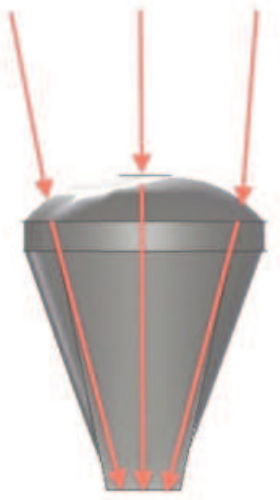

Figure 7: Schematic diagram of the moulded refractive secondary

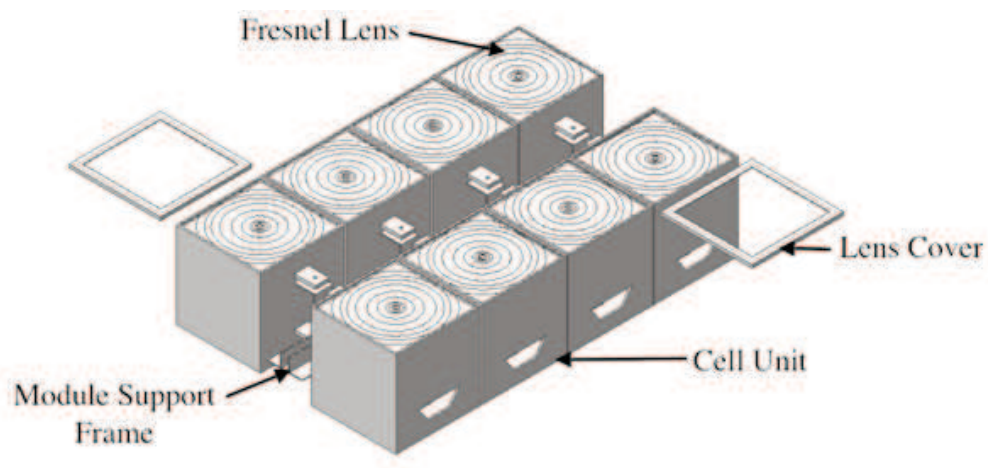

Figure 8: The schematic diagram of the improved CPV module (Module II) with its individual cell units

series for the time of operation. Table 1 shows the summary of the components and operational concentration factors for the two prototype modules.

\section{Experimental procedure}

\subsection{Module I}

On the completion of the design and fabrication of Module I, the electrical characteristics of the CTJ cells where determined, this included:

- An investigation of the effect of the variation in concentration on the performance of power conducted on a cell level. This was achieved by the variation of the Fresnel lens's focal length relative to the cell and obtaining corresponding I-V curves. The information extracted from the I-V measurements provided the current, power and efficiency of the CTJ cell. Plotting the concentration factor as defined in Equation 4 versus efficiency, the effect of concentration could be identified.

- An investigation of the effect of optical misalignment on the performance of an individual CTJ cell and a series connected 2 cell module. The investigation included the comparison of $\mathrm{I}-\mathrm{V}$ measurements of an optically aligned cell unit to a cell unit where the reflective secondary was purposely misaligned. I-V measurements of a series-connected optically aligned cell units were compared to the later configuration where one of the cell unit's reflective secondary was purposely misaligned; and

- Long-term monitoring for individual CTJ cells. The monitoring included the comparison of I-V measurements taken weekly for 2 month period.

\subsection{Module II}

Based on the outcomes and shortfalls experienced in Module I, Module II was designed to improve the performance of CTJ cells under operation. The experiment performed with Module II included long-term monitoring of different cell units within Module II, operating under 2 specific optical conditions (modes). These are:

- An optimal configuration of the optics where the cell unit is optically aligned for optimal performance from the cell unit. This was conducted under operation with sufficient thermal management; and

- An intentional optical misalignment of both the primary and secondary optics of the cell unit. This was conducted under operation with sufficient thermal management.

I-V measurements of each cell unit were taken at periodic intervals of approximately 30 sun-hours for a duration of two and a half months with a total operation of 228 sun-hours. I-V measurements were normalized with respect to the short circuit current and open circuit voltage. This allowed for a visual representation of the decrease in performance (if any) of the cell unit over time.

\section{Results}

\subsection{Module I}

i) The effect of concentration

The results that follow show the effect of solar concentration on the performance of a CTJ cell. In

Table 1: A summary of the components and operational concentration factors for Module I and II

\begin{tabular}{lcc}
\hline Parameter & Module I & Module II \\
\hline Maximum $\mathrm{X}_{\mathrm{o}}$ & 336 & 225 \\
\hline Primary Optical Element & 3M Fresnel Lens in a 2x4 parquet array & Basic PMMA single Fresnel lens \\
\hline Secondary Optical Element & Reflective, aluminium, truncated pyramid & $\begin{array}{c}\text { Refractive, low iron glass, } \\
\text { moulded pyramid }\end{array}$ \\
\hline CTJ Receiver & Emcore CTJ cell (InGaP/InGaAs/Ge) & Emcore CTJ cell (InGaP/InGaAs/Ge) \\
\hline
\end{tabular}


Figures 9 and 10, the one-sun and $336 \mathrm{X}_{\mathrm{o}} \mathrm{I}-\mathrm{V}$ characteristic curves for a CTJ cell are shown.

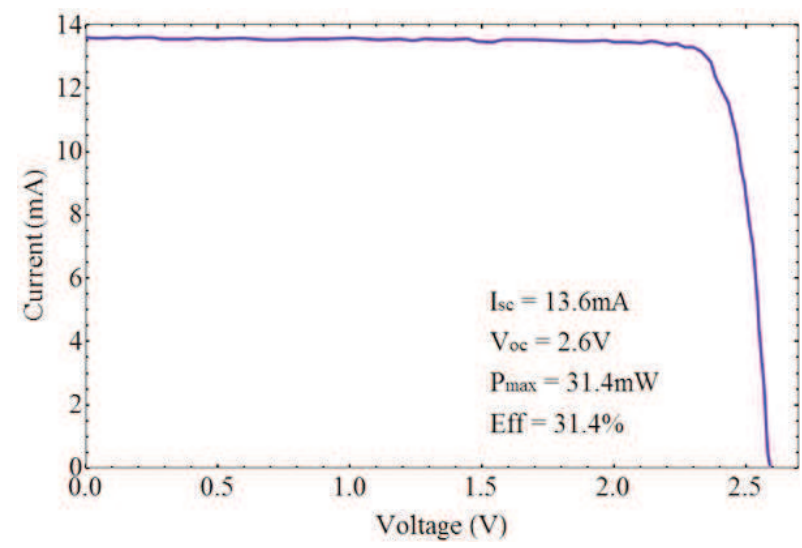

Figure 9: The normalized I-V curve with respect to irradiance and temperature of a CTJ cell at 1 $X_{o}$ concentrations

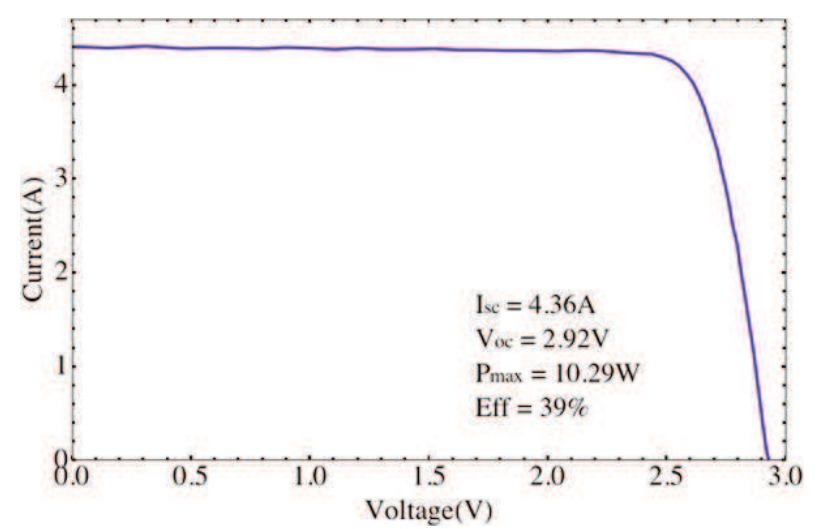

Figure 10: I-V curve of an operational CTJ cell at $336 X_{0}$ concentrations

The performance parameters at one-sun and under concentration, together with those at $124 \mathrm{X}_{\mathrm{o}}$, are listed in Table 2.

Table 2: The effect of the increase operational concentration on I-V parameters of a CTJ cell

\begin{tabular}{lccc}
\hline & $\begin{array}{c}1 \mathrm{X}_{o} \\
\text { concentration }\end{array}$ & $\begin{array}{c}124 \mathrm{X}_{o} \\
\text { concentration }\end{array}$ & $\begin{array}{c}336 \mathrm{X}_{\mathrm{o}} \\
\text { concentration }\end{array}$ \\
\hline Efficiency & $31.4 \%$ & $37.7 \%$ & $39 \%$ \\
\hline $\mathrm{V}_{\mathrm{oc}}$ & $2.58 \mathrm{~V}$ & $2.76 \mathrm{~V}$ & $2.92 \mathrm{~V}$ \\
\hline $\mathrm{I}_{\mathrm{sc}}$ & $13.85 \mathrm{~mA}$ & $1.612 \mathrm{~A}$ & $4.36 \mathrm{~A}$ \\
\hline Power & $31.4 \mathrm{~mW}$ & $3.62 \mathrm{~W}$ & $10.29 \mathrm{~W}$ \\
\hline
\end{tabular}

Under concentration, as observed in Figures 9 and 10, the $\mathrm{I}_{\mathrm{sc}}$ is increased by a factor of $336 \mathrm{X}_{\mathrm{o}}$ and the $\mathrm{V}_{\mathrm{oc}}$ is increased from $2.58 \mathrm{~V}$ to $2.92 \mathrm{~V}$. The increase in $\mathrm{I}_{\mathrm{sc}}$ is due to the increase in incident irradiance on the $1 \mathrm{~cm}^{2}$ CTJ device resulting from the concentration of sunlight by the optics. This is evident from Equation 5 as the $I_{\mathrm{sc}}$ and $\Phi_{\text {inc }}$ are directly related. Since the $I_{\mathrm{sc}}$ is directly proportional to the concentrated incident irradiance, it will increase lin- early with concentration (Hegedus. \& Luque, 2002; Cotal et al., 2009; Chong \& Siaw, 2008). The logarithmic increase observed in the $V_{o c}$ is due the increased in $\mathrm{I}_{\mathrm{sc}}$ with increasing irradiance (Cotal et al., 2009; Kinsey et al., 2009). The $\mathrm{V}_{\mathrm{oc}}$ increases slowly (logarithmically) with increasing photo-current if dark current remains constant at the cell operating temperature. Hence, a CTJ cell at a concentration of $336 \mathrm{X}_{\mathrm{o}}$ will see an increase in $\mathrm{V}_{\mathrm{oc}}$ of tens of $\mathrm{kT} / \mathrm{q}$ at a constant operating temperature (refer Equation 9).

Hence, the quality of the optics to concentrate sunlight will affect the increase in the $\mathrm{I}_{\mathrm{sc}}$ and $\mathrm{V}_{\mathrm{oc}}$. For Module I, the results showed an increase in the power output from $31 \mathrm{~mW}$ to $10.29 \mathrm{~W}, 343$ times greater than at one-sun. The efficiency increases from $31 \%$ to $39 \%$. Figure 11 shows the CTJ cell's efficiency as a function of increasing concentration.

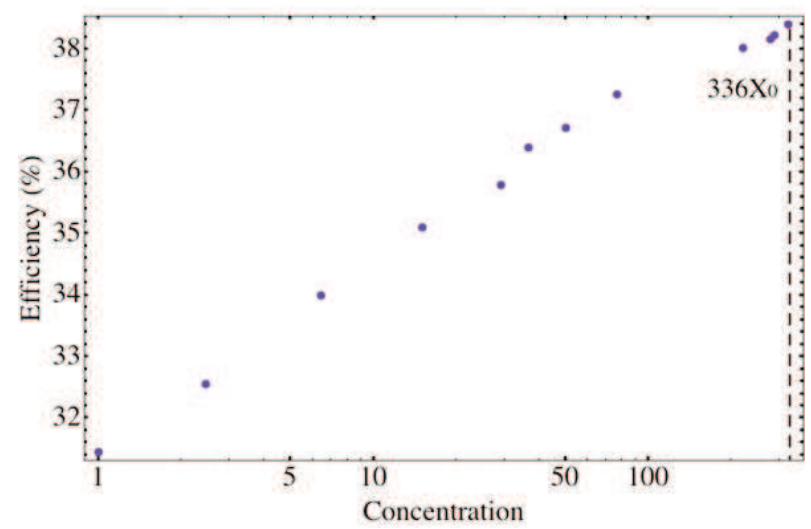

Figure 11: The increase in efficiency of a CTJ cell with the increase in concentration

From Figure 11, it is observed that the efficiency increases linearly with concentration. The increase in the efficiency is attributed to the combined effect of the increase in both the $\mathrm{I}_{\mathrm{sc}}$ and $\mathrm{V}_{\mathrm{oc}}$ due to concentration, with the latter being the primary contributor. From Equation 12, it can be approximated that the $\mathrm{I}_{\max }=\mathrm{X}_{\mathrm{o}} . \mathrm{I}_{\mathrm{sc}}$. Substituting for $\mathrm{I}_{\max }$, one can readily see that the $\mathrm{X}_{\mathrm{o}}$ cancel and the only contributing factor to the increase in efficiency is the $V_{\text {max. }}$. As explained above, the $V_{\text {max }}$ increases with the logarithmic increase in $\mathrm{V}_{\mathrm{oc}}$, due to the increase in $I_{s c}$ with irradiance.

\section{ii) Long-term measurements.}

In order to assess the reliability and performance of Module I, the performance of single cells within the module were monitored over a 2 month period. Figure 12 shows the initial I-V characteristics, under concentration, of 2 individual cells in an optically aligned system before and after (shown with*) the 2 -month operational period. Table 3 summarizes the parameters of the CTJ cells before and after an operational period. 


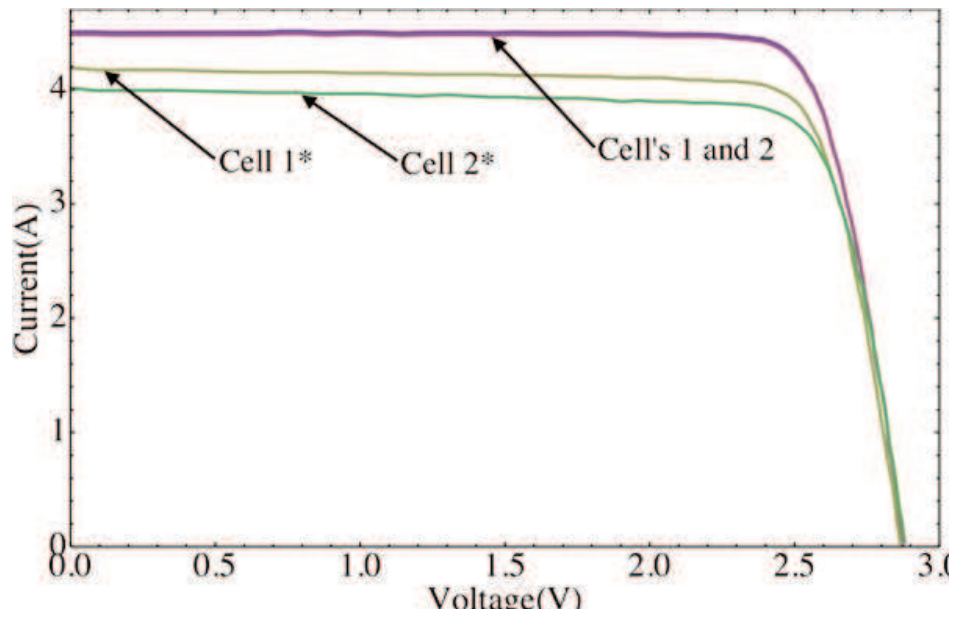

Figure 12: Graphs showing the CTJ cell I-V curves of Module I before and after a period of 2 months in operation

Table 3: The difference in the device parameters of 2 CTJ cells after 2 months of operation

\begin{tabular}{lcccc}
\hline Parameter & Before & After & Before & After \\
\hline & Cell 1 & Cell 1* & Cell 2 & Cell 2* \\
\hline Current (A) & 4.43 & 4.21 & 4.43 & 4.05 \\
\hline Voltage (V) & 2.82 & 2.92 & 2.82 & 2.88 \\
\hline Power (W) & 10.02 & 9.10 & 10.02 & 8.98 \\
\hline
\end{tabular}

As observed in Figure 12, the performance of cells 1 and 2 are identical at the start of the monitoring period. However, after 2 months of operation, there was a decrease in performance of both cells. The decrease observed in the performance parameters of both cells, $I_{\mathrm{sc}}$ and $\mathrm{P}_{\max }$, was attributed to possible soiling of the reflective secondary and/or cell damage. Upon removing the visible soiling from the reflective secondary and cell surfaces, the cause of the reduction of the performance parameters was established by comparing I- $V$ characteristics measured at one-sun and at concentration before and

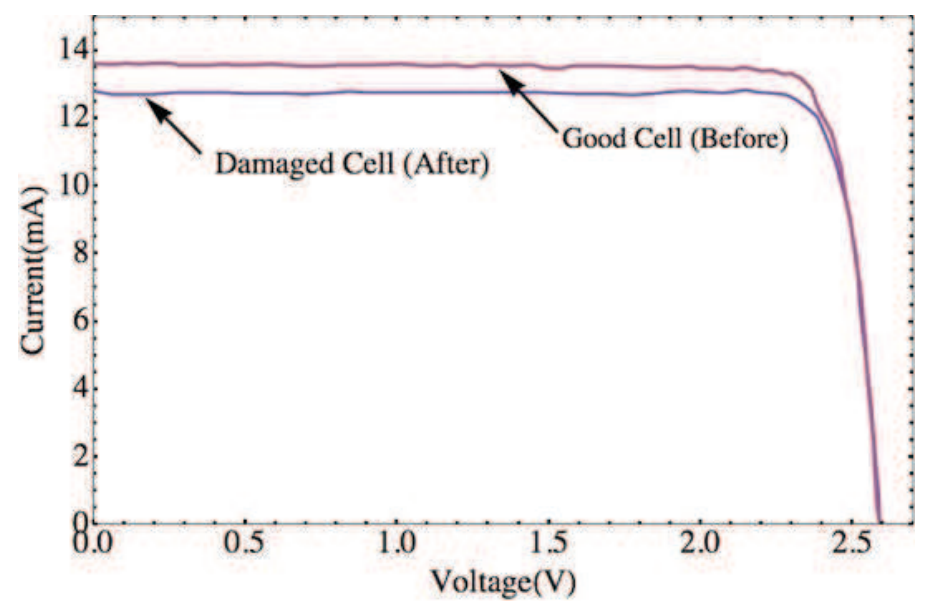

Figure 13: Graph showing the decrease in the I-V curve of cell 2 due to cell damage after the monitoring period. Cell 1 showed no signs of any reduction in $P_{\max }$, but cell 2 was reduced by $1.7 \mathrm{~mW}(6 \%)$ at one-sun. Figure 13 shows the I-V characteristics of cell 2 before and after the evaluation period.

The decrease in $\mathrm{P}_{\max }$ observed for cell $1^{*}$ as seen in Figure 12 must therefore be due to soiling of the optical system and cell itself. The Fresnel lens and the reflective secondary were, indeed, soiled, and the cell also had noticeable soiling. This leads to a decrease of almost $10 \%$ in power from the cell. Hence, it would be beneficial to the performance if one can eliminate the effect of soiling on the optics and cells. This will also contribute to low maintenance of the module.

The reduction in the performance parameters of cell 2 is due to the combination of soiling and noted cell damage. The cell damage may be due to deflects induced by unintentional misalignment in the optical system. The effect of the misalignment will result in the formation of non-uniformities or a localized, high intensity region. This region will thus cause that part of the CTJ cell to operate 'harder' than the rest of the cell. Depending on the degree of misalignment, the concentrated beam my create hotspots which may result in damage of the cell. This misalignment may in turn cause current mismatch within the cell that may induce material damage.

\section{iii) Optical misalignment}

Figure 14 shows the effect of optical misalignment on the I-V characteristics and power production of a CTJ cell. The difference in the I-V curves results from a shift of the intensity distribution from being symmetrical to being less symmetrical across the cell (Vorster, 2001).

Figure 15 shows the illumination distribution across the cell for the a) aligned and b) misaligned optical configuration. Although the magnitude of the maximum relative intensities is very similar, the photo-generated current produced is much less when the intensity distribution is less uniform. It appears that a less symmetrical distribution causes the shunt slope of the I-V curve to increase.

Efficiencies of $36.8 \%$ and $35.2 \%$ were achieved for the aligned and misaligned secondary setup, respectively. The decrease in $V_{\text {oc }}$ observed from the misaligned setup is due to the logarithmic dependence of the output voltage on the effective concentration as a function of the $\mathrm{I}_{\mathrm{sc}}$. Hence, due to misalignment, the overall photon flux onto the CTJ receiver is much less, resulting in a decreased $\mathrm{I}_{\mathrm{sc}}$ and $\mathrm{V}_{\text {oc }}$. This would lead to a much lower $\mathrm{P}_{\max }$ and thus a reduced efficiency (Schultz et al., 2011; Luque \& Sala, 1998).

The above result is made even more apparent when compared to that of a two-cell test series connected module with bypass diodes. Figure 16 shows 


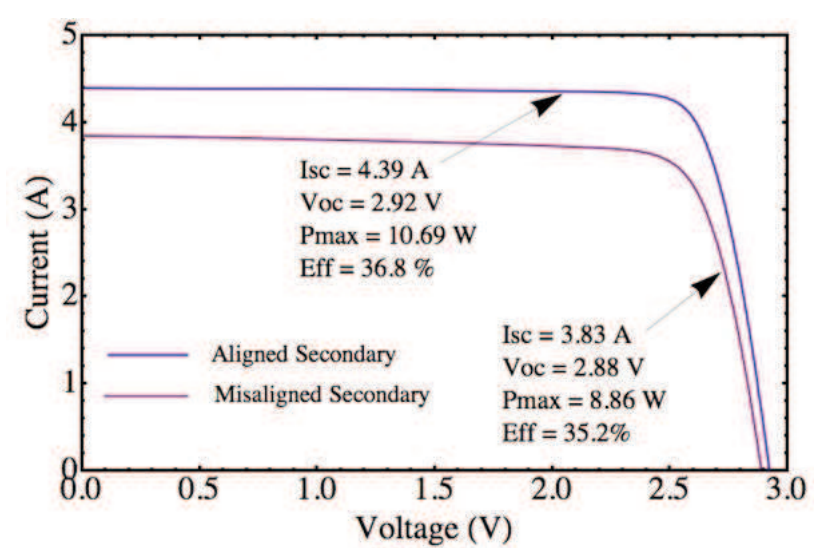

Figure 14: I-V characteristics of the effects of misalignment reflective secondary on a CTJ cell

the I-V characteristics of the test module under the best conditions and with intentional misalignment of one reflective secondary.

The effect of current bypassing the cell that produced the lowest short circuit current can be seen as a perturbation in the measured I-V curve indicated by the step. The current mismatch caused a $2.23 \mathrm{~W}$ loss, a $13.2 \%$ decrease in the power production relative to the best-aligned module with no misalignment or mismatch. Although this decrease in performance in the 2 cell module does not appear to have a great effect to power production, on a larger modular scale, i.e. a 16 cell series connected module, optical misalignment may affect the performance greatly. Hence, the correlation between the optical alignment and performance of the cell shows that proper optical alignment is important for the optimal functioning of a CPV module.

\subsection{Module II}

To evaluate the performance of the improved CPV module, I-V characteristics before and after the 2.5 month operational period were compared with a

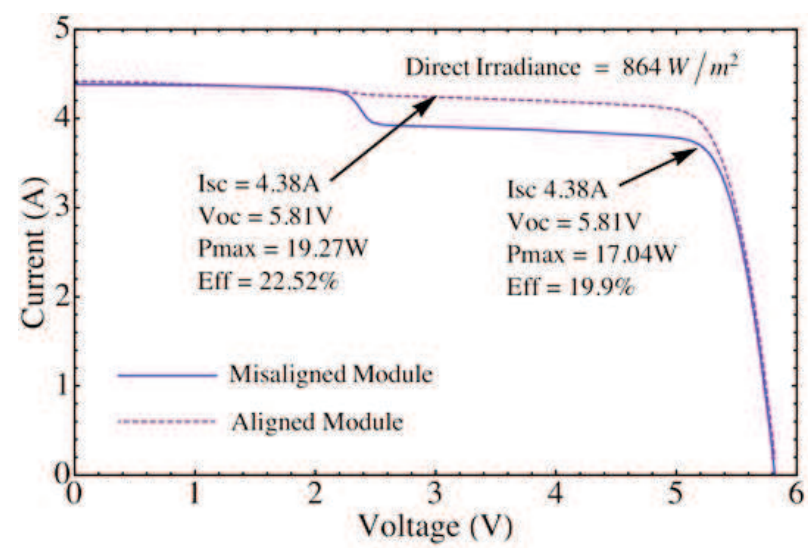

Figure 16: I-V characteristics of Module I showing the effect of misalignment on a 2-cell CPV module

total operation period of 228 sun-hours. Since the performance of the cells within the module were obtained at different irradiance and concentration values, the I-V curves were normalized with respect to $\mathrm{I}_{\mathrm{sc}}$ and $\mathrm{V}_{\mathrm{oc}}\left(\mathrm{I} / \mathrm{I}_{\mathrm{sc}}\right.$ and $\left.\mathrm{V} / \mathrm{V}_{\mathrm{oc}}=1\right)$.

\section{i) Optimal operation mode of cell unit}

Figure 17 shows the normalized I-V characteristics of one cell being operated under optimal conditions before and after the operational period.

It is noticed from the normalized curves that there is little deviation in the shape of the I-V curves from 4 to 228 sun-hours. The small deviation observed from the curve at 4 sun-hours may be attributed to the influence of the optical system, such as soiling of the refractive secondary. Although the operational mode for this cell was to have an optimal optical configuration, the optics may not optimal. There may be areas across the cell that have non-uniform illumination. This non-uniformity distribution of irradiance may cause the shunt slope of the I-V curve to increase due to the effect of localized photo-current mismatch which may

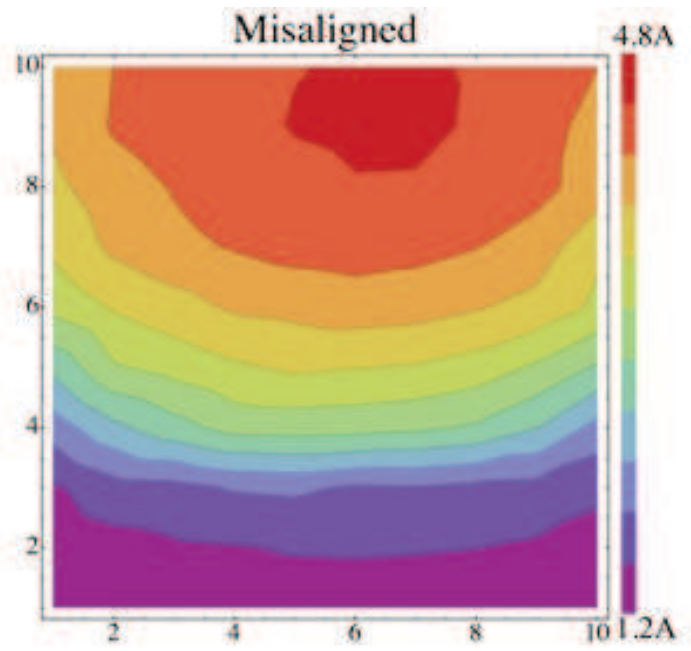

Figure 15: The illumination distribution across the cell for the a) aligned and b) misaligned optical configuration 


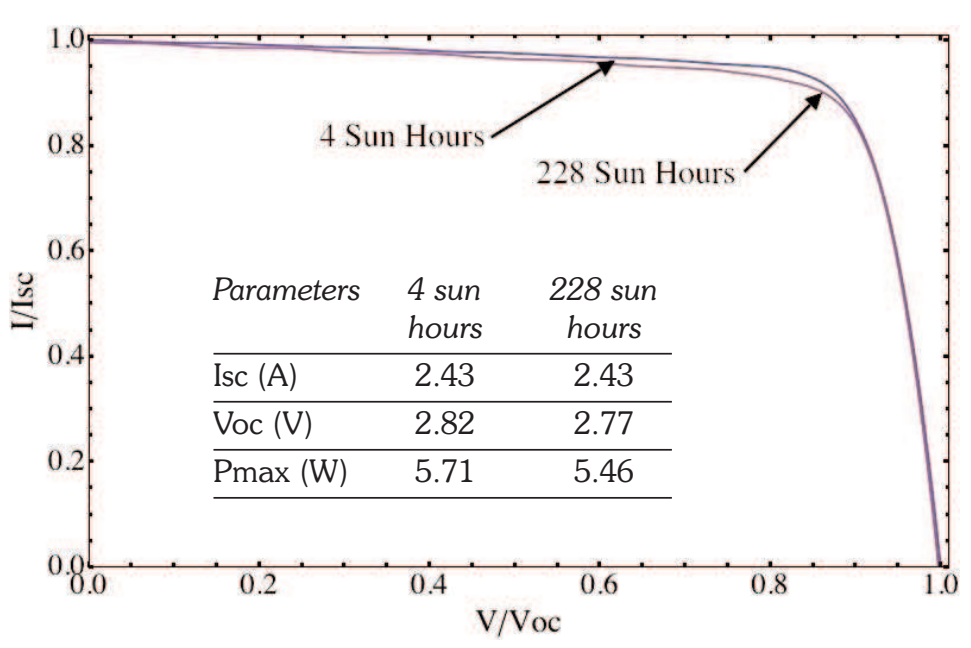

Figure 17: I-V characteristics for a CTJ cell at different sun hours for the optimal unit set up

promote degradation. The table within the graph indicated that there is a small change in the normalized $\mathrm{I}_{\mathrm{sc}}$ (to $850 \mathrm{~W} \cdot \mathrm{m}^{-2}$.) This small variation can also be attributed to the optical illumination pattern. As a result of this illumination pattern, certain areas within the CTJ cell may experience a form of cell damage/ or the start of defects within device to occur.

However, a combination of good thermal dissipation and optical alignment has given the best operational module (Vincenzo Fracastoro et al., 2009).

\section{ii) Optical misalignment operation mode of cell} unit

Figure 18 shows the normalized I-V characteristics of the optically misaligned cell mode before and after the operational period.

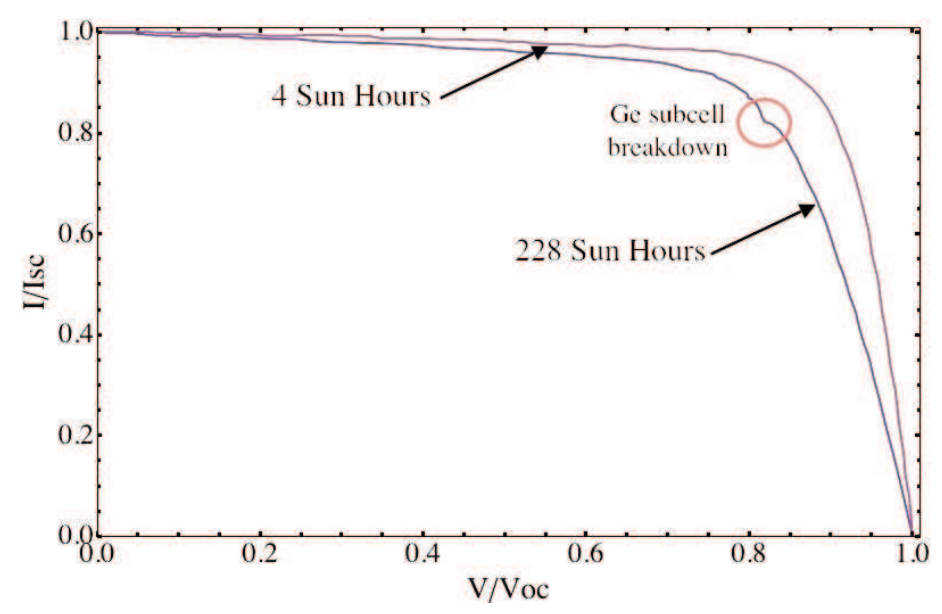

Figure 18: I-V characteristics for a CTJ cell at different sun hours for the optically misaligned unit set up

It is observed from Figure 18 that there is a difference in the shape of the final normalized I-V curve after 228 sun-hours when compared to the one after 4 sun-hours. The decrease in performance before and after the operation period for the mis- aligned cell is summarized within Figure 18. The optical misalignment may cause the formation or enhancement of defects within the CTJ cell. These defects act as recombination sites that may reduce the current production of the CTJ cell. Coupled with the variation in illumination intensity across the cell surface, there will be a resulting decrease in the shunt resistance.

Additionally, there is a noticeable change in the I-V characteristics with shift of the 'knee' or maximum power point. This observed shift is attributed to a decrease in shunt resistance, possibly caused by induced defects in the CTJ cell resulting from the non-uniform intensity distribution. This decrease will reduce the power production of the CTJ cell with increased irradiance exposure. The kink that is observed is possibly due to the breakdown of one of the sub-cells in the CTJ cell. Since the kink appears at a voltage of $2.42 \mathrm{~V}$ on the measured I-V curve after 228 sun-hours and the Ge has the smallest voltage contribution of $0.2 \mathrm{~V}$ (Hegedus. \& Luque, 2002), it is prDoposed that the Ge sub-cell is undergoing breakdown. If the breakdown occurred in any other sub-cell, the kink would be seen at a $\mathrm{V}<\mathrm{V}_{\max }$ because both the other sub-cells have voltages greater than $1 \mathrm{~V}$. The direct cause of the sub-cell breakdown is not certain. All these effects lead to a power decrease of $13.2 \%$.

It may, therefore, it can be deduced that a CTJ cell operating under some form of optical stress develops defects. It is proposed that these defects are induced from thermal stresses on the device caused by thermal gradients created within the CTJ cell by optical misalignment. Optical misalignment, even with a sufficient heatsink will generate temperature gradient regions within and between the subcell layers. These temperature gradients will have a negative effect on the performance of each sub-cell and CTJ cell.

\section{Conclusion}

The performance results obtained from Module I and II show that the best configuration for optimal CPV module performance must consist of good optical alignment, which produces a uniform intensity and irradiance pattern. This was confirmed by the I-V characteristics during the operational periods of both experimental modules. Coupled with a sufficient thermal dissipation system, the performance, reliability and longevity of a CTJ cell/ module will be increased significantly if optimally aligned.

However, a CTJ cell operating under optical misalignment showed a progressive decrease in power with prolonged operational exposure in both module systems. This decrease in performance was attributed to the possibility of induced or the enhancements of defects. These defects can act as recombination sites resulting in a lower current production. 
In conclusion, to ensure the best design and to achieve the best performance from a CPV module, it is recommended that the characterisation of the whole optical system (the primary and secondary combined) be performed. This characterization will allow one to identify faulty optics so that they may be eliminated from the CPV system and allow for the best CPV modules to be deployed in the field for maximum energy yield. This is important at present as with recent developing technology of the multi-junction cell reaching $44.7 \%$ and $37 \%$ on a cell and module level, respectively, the power generation of the CPV system may be increased greatly. Additionally, this will allow for reliable systems to be deployed in South Africa to aid in meeting the goals set by government to have continuous uninterrupted power.

\section{References}

Alanod material properties, viewed 10 December 2010, http://www.alanod-solar.us/reflection-products.php

Chong K.K \& Siaw F.L., (2008). Design and construction of non-imaging planar concentrator for concentrator photovoltaic system, Renewable Energy, 34, 1364-1370.

Cotal, C. Fetzer, J. Boisvert, G. Kinsey, R. King, P. Hebert, H. Yoon \& N. Karam, (2009).III-V multijunction solar cells for concentrating photovoltaics, Energy \& Environmental Science, 2, 174-192.

Emcore datasheet viewed 23 April 2010, http://www.emcore.com/terrestrial-photovoltaics/terrestrial_solar_cells_and_receivers/.

Hegedus, S. \& Luque, A., (2002). Handbook of Photovoltaic Science and Engineering, Wiley.

IME Raytrace software, computer software, viewed 23 March 2010, from http://members.ozemail.com.au/ imesoft/.

Integrated Resource Plan for electricity 2010-2030, viewed 10 November 2014, http://www.energy.gov.za/IRP/irp\%20files/IRP2010_2 030 Final Report 20110325.pdf.

Kinsey, G. \& Edmondson, K., (2009). Spectral Response and Energy Output of Concentrator Multijunction Solar Cells, Progress in Photovoltaics, 17, 279-288.

Kost, C.; Mayer, J.; Thomsen, J.; Hartmann, N.; Senkpiel, C.; Philipps, S.; Nold, S.; Lude, S.; Saad, N.; Schmidt, J. \& Schlegl, T. Levelized Cost of Electricity: PV and CPV in Comparison to Other Technologies EU PVSEC 2014, Amsterdam, 2014

Kwangsun Ryu, Jin-Geun Rhee, Kang-Min Park \& Jeong Kim, (2006). Concept and design of modular Fresnel lenses for concentration solar PV system, Solar Energy, 80, 1580-1587.

Leutz R. \& Rhodes, A. (2001). Nonimaging Fresnel Lenses: Design and performance of Solar Concentrators, Springer.

Luque, A. \& Sala, G. (1998). Electric and thermal model for non-uniformly illuminated concentration cells, Solar Energy Materials and Solar Cells, 51, 269-290.
Lorenzo, E., (1994). Solar Electricity: Engineering of Photovoltaic Systems, Progensa.

Nrel data sheet, viewed 15 June 2012, http://science.gov.tm/projects/soltme/images/database/35 nrel.pdf

Rumyantsevm, V.D., Andreev, V.M. \& Grilikhes, V.A., (1997). Photovoltaics Conversion of Concentrated Sunlight, Wiley.

Schultz, R.D., Vorster, F.J. \& van Dyk, E.E., (2011). Performance of multi-junction cells due to illumination distribution across the cell surface, Physica $B$.

Soitec announces full commissioning of 22MWp on Touwsrivier solar plant in South Africa, viewed 15 July 2014, http://www.soitec.com/en/news/pressreleases/soitec-announces-full-commissioning-of22mwp-on-touwsrivier-solar-plant-in-south-africa$1456 /$.

Ventre, J. \& Messenger, R.A., (2005). Photovoltaic Systems Engineering, CRC Press LLC.

Vincenzo Fracastoro, G., Zubi, G. \& Bernal-Agustin, J. L, (2009). High concentration photovoltaic systems applying iii-v cells, Renewable and Sustainable Energy Reviews, 13:2645-2652.

Vorster, F.J. (2001). On the evaluation of a photovoltaic concentrator system, Master's thesis, department of Physics, Nelson Mandela Metropolitan University

Xie, W.T. Dai, Y.J., Wang, R.Z., \& Sumathy, K. (2011). Concentrated solar energy applications using Fresnel lenses: A review, Renewable and Sustainable Energy Reviews, 15, 2588-2606.

Received 13 June 2013; revised 3 March 2015 